\title{
Hollowfiber Polyurethane-Collagen Coating Chitosan as Nerve Graft for Therapy of Peripheral Nerve Injury in Extreme Paralysis
}

\author{
Hendita Nur Maulida ${ }^{1}$, Fitriyatul Qulub ${ }^{1}$, Azizah Fresia Rosdiani ${ }^{1}$, \\ Disca Sandyakala Purnama ${ }^{1}$, Karina Dwi Saraswati ${ }^{1}$, Prihartini Widiyanti ${ }^{1,2}$ \\ ${ }^{1}$ Biomedical Engineering Study Program, Faculty of Science and Technology, \\ Universitas Airlangga, Surabaya, Indonesia \\ ${ }^{2}$ Institute of Tropical Disease, Universitas Airlangga, Surabaya, Indonesia \\ Corresponding author: pwidiyanti@fst.unair.ac.id
}

Keywords: peripheral nerve injury, hollowfiber, polyurethane, collagen, chitosan, nerve graft

\begin{abstract}
Peripheral nerve injury with gaps between 5 and $30 \mathrm{~mm}$ can result in permanent paralysis because axons are cut. The distance between axons, which is more than $1-2 \mathrm{~cm}$, needs graft in the form of nerve connecting pipe in order to repair the defects. A synthesis of hollowfiber polyurethane-collagen coated by chitosan was carried out to identify its potential as treatment accelerator for peripheral nerve injury. The result of Fourier Transform Infrared (FTIR) analysis showed multiple links between chitosan and glutaraldehyde, which can be seen in wavenumber shift from $1080-1100 \mathrm{~cm}^{-1}$ to $1002 \mathrm{~cm}^{-1}$. The degradation test result revealed that the sample displayed mass loss after it was soaked in simulated body fluid (SBF) for seven days. Polyurethane can be degraded in the body after 30 days. This converges with the nerve mechanism that regenerates at the rate of $1 \mathrm{~mm} /$ day or $1 \mathrm{inch} / \mathrm{month}$. The result of tensile test indicated that modulus values of chitosan coating variation of $1 \%, 1.5 \%$, and $2 \%$ were $4.75 \mathrm{MPa}, 4.74 \mathrm{MPa}$, and $7.67 \mathrm{Mpa}$ respectively. The outcome of scanning electron microscope (SEM) showed that hollow fiber has a diameter of 2.021-2.032 mm, which matches the diameter of peripheral nerves ranging from 1.5 to $3 \mathrm{~mm}$ and the membrane pore size of 31.33-39.65 $\mu \mathrm{m}$. The result of MTT assay demonstrated that the percentage of viable fibroblast BHK-21 cells was exceeding 50\%, which means that the sample does not have toxic properties. The result of this study is expected to provide theoretical basis for the utilization of polyurethane-collagen coating chitosan as nerve graft for theraphy of peripheral nerve injury. The utilization is possible due to the fact that the composite exhibits biocompatible, regenerative, and easily degradable characteristics. Moreover, it could become an alternative solution to answer the need of a more affordable and easier-to-produce nerve graft, so it can be mass-produced in Indonesia.
\end{abstract}

\section{Introduction}

Indonesian Central Bureau of Statistics reported that as many as 69,260 road traffic accident cases happened in 2009 and 66,488 cases in 2010 involving major injuries in extremity parts [1]. Peripheral nerve injury with gaps between 5-30 mm, whether it occurs because of direct injury $(87 \%)$ or medical misdiagnosis $(12 \%)$, receives special attention because it can cause paralysis or permanent disability. Some of the injuries are often found in peripheral nerves. Peripheral nerve injury can result from road accident, work accident, surgery complication or cuts from sharp-edged objects, all of which can cause motor and sensory paralysis, disrupting someone's ability to do activities normally [2].

Nerve regeneration occurs at a rate of $1 \mathrm{~mm} /$ day or $1 \mathrm{inch} / \mathrm{month}$ [3]. Injured peripheral nerves have distinct neuronal and axonal responses. The severity of injury partly determines axon regeneration rate. Although the growth rate of axon and motor function maturation are slow, regeneration rate can be forecasted. In mild peripheral nerve injuries, nerves are still able to regenerate. However, severe peripheral nerve injuries induce cut axons, so there are cracks or gaps in nerves. Gaps in nerve axons can be found in approximately $5 \%$ of all peripheral nerve injury cases [3]. The gaps between two axons that is more than $1-2 \mathrm{~cm}$ requires graft in the form of nerve connecting pipe to ligate the severed nerves [4]. 
Until present day, autologous nerve grafting or nerve autograft is known as the gold standard of treatment and lesion reparation in peripheral nerves with large gaps. A segment of unrelated nerves is extracted from other body parts and filled in lesions to provide endoneurial tube for axon regeneration. Nevertheless, this method is not a perfect therapy because it often only restores the function in limited way. The limited function that autograft can restore encouraged the writers to invent bioartificial nerve guidance conduit that mostly uses chitosan-based materials. Cui et. al.at 2009 successfully fabricated double-layer nerve conduit by using polyurethane in outer layer and collagen in inner layer with the technique of double-nozzle low-temperature deposition manufacturing. Schwann cells from rat nerves, which were cultured in the conduit of polyurethanecollagen composites for one week, experienced significant improvement in terms of retention and viability than those in pure polyurethane conduit. Hence, it has huge potential in clinical application of peripheral nerve repair [5].

Based on the aforementioned problem, this research aims to manufacture an accelerator of peripheral nerve injury treatment made of polyurethane (PU)-collagen composites coated with chitosan. Polyurethane was selected due to its flexible degradation rate. In order to ensure nerve cells to regenerate, the selected materials must be impermanent and degradable so that no repeated surgery takes place to take polymer remnants after completed nerve regeneration process. According to the study of Cui et. al., polyurethane matrix is mechanically stable when it interacts with in vivo condition; on the other hand, collagen filler will repair its material-biological properties because it stimulates Schwann cell adhesion, migration and proliferation. Coating with chitosan was done because of its biocompatible characteristic, its resemblance with extracellular matrix in body, and its crucial role as antimicrobial. Besides, the in vitro study showed the suitability of chitosan membrane as substrate to survive and be oriented in the growth of Schwann cells [6] as well as viability and differentiation of nerve cells [7]. Before coating, chitosan would be crosslinked with glutaraldehyde in order to improve its mechanic feature. Glutaraldehyde is very reactive towards amines group in chitosan, so they will form bridge that connects one chitosan polymer with the others when they are reacted [8]. The characterisation in this study involves functional group analysis, bioactivity test, tensile test, morphology test, and cytotoxicity test.

\section{Research method}

\section{Equipment and materials}

The equipment used in the present study consisted of Mettler Toledo digital scale, magnetic stirrer Yellow MAG HS 7, spinneret, microwave, dip coating equipment, $\mathrm{pH}$ meter Benchtop OAKTON, Fourier transform infrared Perkin Elmer, a set of tensile test equipment IMADA Japan, scanning electron microscope Inspect S50 FEI and a set of MTT Assay equipment.

The materials used in the present study were polyurethane Sigma Aldrich 81367, collagen of seabass scales from National Nuclear Energy Agency (BATAN) Jakarta, chitosan from PT. Biochitosan Indonesia, glutaraldehyde 25\% Merck 104239, chloroform, toluene, citric acid, acetic acid, aqua dest, aqua bidest, materials to make simulated body fluid solution $\left(\mathrm{NaCl}, \mathrm{NaHCO}_{3}, \mathrm{KCl}\right.$, $\mathrm{K}_{2} \mathrm{HPO}_{4} \cdot 3 \mathrm{H}_{2} \mathrm{O}, \mathrm{MgCl}_{2} \cdot 6 \mathrm{H}_{2} \mathrm{O}, \mathrm{HCl}, \mathrm{CaCl}_{2} \cdot 2 \mathrm{H}_{2} \mathrm{O}, \mathrm{Na}_{2} \mathrm{SO}_{4}$ and $\left.\left(\mathrm{HOCH}_{2}\right)_{3} \mathrm{CNH}_{2}\right)$.

\section{Synthesis of Hollowfiber Polyurethane-Collagen with Chitosan Coating}

Hollowfiber polyurethane was fabricated with spinneret by dissolving $5 \%(\mathrm{w} / \mathrm{v})$ polyurethane in chloroform $5 / 6(\mathrm{v} / \mathrm{v}$, and toluene $1 / 6(\mathrm{v} / \mathrm{v}) .2 \%(\mathrm{w} / \mathrm{v})$ collagen in $2 \%(\mathrm{w} / \mathrm{v})$ citric acid was filled in polyurethane tube, frozen at a temperature of $5^{\circ} \mathrm{C}$ for 24 hours, and dried in oven at $60^{\circ} \mathrm{C}$ temperature for 2 hours. As coating, chitosan was dissolved based on composition variations $(1 \%$, $1,5 \%$ and $2 \%)(\mathrm{w} / \mathrm{v})$ in $1 \%$ acetic acid solution and crosslinked with $0.5 \%$ glutaraldehyde $(\mathrm{w} / \mathrm{v})$ in order to do coating for 2 hours. Drying was carried out in oven with the temperature of $60^{\circ} \mathrm{C}$ for 2 hours, and sample was ready to be characterized. 


\section{Functional Group Analysis with Fourier Transform Infrared (FTIR)}

FTIR was conducted to analyse functional group of the materials and the possibility of new bond formation. The sample was taken in a small intake and added with $\mathrm{KBr}$ powder as background. The sample was then compacted with hydraulic pump and placed on specimen holder to be irradiated with infrared. The obtained result was absorbance region graphic of wavenumber $\left(\mathrm{cm}^{-1}\right)$ towards transmittance percentage $(\%)$.

\section{Degradation Test with Simulated Body Fluid (SBF)}

Table 1. Composition of Chemical Constituents of SBF Solution

\begin{tabular}{|c|c|c|}
\hline No. & Chemical & Composition \\
\hline 1. & $\mathrm{NaCl}$ & $7.996 \mathrm{~g}$ \\
\hline 2. & $\mathrm{NaHCO}_{3}$ & $0.350 \mathrm{~g}$ \\
\hline 3. & $\mathrm{KCl}$ & $0.224 \mathrm{~g}$ \\
\hline 4. & $\mathrm{~K}_{2} \mathrm{HPO}_{4} .3 \mathrm{H}_{2} \mathrm{O}$ & $0.228 \mathrm{~g}$ \\
\hline 5. & $\mathrm{MgCl}_{2} \cdot 6 \mathrm{H}_{2} \mathrm{O}$ & $0.305 \mathrm{~g}$ \\
\hline 6. & $\mathrm{CaCl}_{2} .2 \mathrm{H}_{2} \mathrm{O}$ & $0.278 \mathrm{~g}$ \\
\hline 7. & $\mathrm{Na}_{2} \mathrm{SO}_{4}$ & $0.071 \mathrm{~g}$ \\
\hline 8. & $\left(\mathrm{HOCH}_{2}\right)_{3} \mathrm{CNH}$ & $6.057 \mathrm{~g}$ \\
\hline 9. & $\mathrm{HCl} 1 \mathrm{M}$ & $40 \mathrm{ml}$ \\
\hline
\end{tabular}

Degradation test was administered to investigate bioactivity capability of the materials using simulated body fluid (SBF). The method used to make SBF solution was adopted from the method used by Kokubo, as can be seen in table 1. Chemical substances were put in order, one by one in 1L of destilated water (aquabidestilata). The final volume of the solutions amounted to 1L. Solution temperature was maintained at $37^{\circ} \mathrm{C}$, and solution $\mathrm{pH}$ was adjusted at $\mathrm{pH}$ range of normal body temperature, which is $6.9-7.4$ by using $\mathrm{HCl} 1 \mathrm{M}$ solution. The film sample was cut $(1 \mathrm{x} 1 \mathrm{~cm})$ in every concentration variation of chitosan coating. The mass of the sample was measured and soaked in SBF solution in $5 \mathrm{ml}$ pot bottle. During submersion, SBF solution in pot bottle was changed every 24 hours in order to adjust to liquid condition inside the body. The mass of the sample was measured every 24 hours to understand the material's degradation capability in time unit. After 7 days, the mass of the remaining composites was measured again, and the result was presented in graph of mass change versus time.

\section{Tensile Test}

Tensile test was employed to determine the elongation of the materials when they were implanted in body. Film sample was crafted in dog-bone shaped structure with length of $63.5 \mathrm{~mm}$, width of $10 \mathrm{~mm}$, and gauge length of $5 \mathrm{~mm}$ according to American Society for Testing Material (ASTM D 1822 L) for each variation. The sample was pulled at the speed of $10 \mathrm{~mm} / \mathrm{minute}$ and maximum weight of $50 \mathrm{~N}$.

\section{Morphology Test with Scanning Electron Microscope (SEM)}

SEM test was performed to find out the diameter and pore size of the sample. Before conducting SEM test, the sample was first cleansed and dried; it was then placed on the stake holder that had been covered with gold carbon tip ( $\mathrm{Au}$ ). The size of the stage holder is $12 \mathrm{~mm}$ or $25 \mathrm{~mm}$. Contact area of the sample was made large in order to ease identification process. The sample was examined in the specimen chamber with size below $200 \mathrm{~nm}$, and the result was captured in tiff image format.

\section{Cytotoxicity Test with MTT Assay}

Cytotoxicity test was carried out using MTT reagent \{3-(4.5-dimethyl-2-thiazolyl)-2.5diphenyl-2H-tetrazolium bromide $\}$ that consists of proliferation stage or fibroblast Baby Hamster Kidney (BHK-21) cell culture, sample placement and result reading. 


\section{Fibroblast BHK-21 Cell Culture}

Preparation of cell culture was done in laminar air flow. Cell culture in monolayer with Eagle's media was grown in Roux bottle and given treatment in incubator with temperature of $37^{\circ} \mathrm{C}$ for 48 hours. Afterwards, cell culture was rinsed five times with Phosphate Buffer Saline (PBS) and added with trypsin-versene to release cells from the bottle's wall and separate bond among cells. Cells with density of $2 \times 10^{5}$ was added with Eagle's media and moved to 96-microwell plate with $100 \mu \mathrm{L}$ added to each well.

2. Sample Placement

The sample was put in 96-microwell plate with the size adjusted to well and incubated for 24 hours at $37^{\circ} \mathrm{C}$. Next, the sample in 96-microwell plate was disposed and rinsed with $250 \mu \mathrm{L}$ PBS. 5 $\mathrm{mg} / \mathrm{Ml}$ of MTT reagent, which had been dissolved in PBS, was added to media as much as $10 \mu \mathrm{L}$ and incubated for 3-4 hours at $37^{\circ} \mathrm{C}$. Dimethyl sulfoxide (DMSO) solution was added to stop reaction and shaked at the speed of $30 \mathrm{rpm}$ for 5 minutes.

3. Result Reading

Cell optical density can be determined with a tool named Elisa Reader, and equation (1) was used to calculate percentage of viable cells. A material is deemed non-toxic if the percentage of viable cells exceeds $50 \%$ [9].

\section{Results and discussion}

\section{Analysis Result of Functional Group with Fourier Transform Infrared (FTIR)}

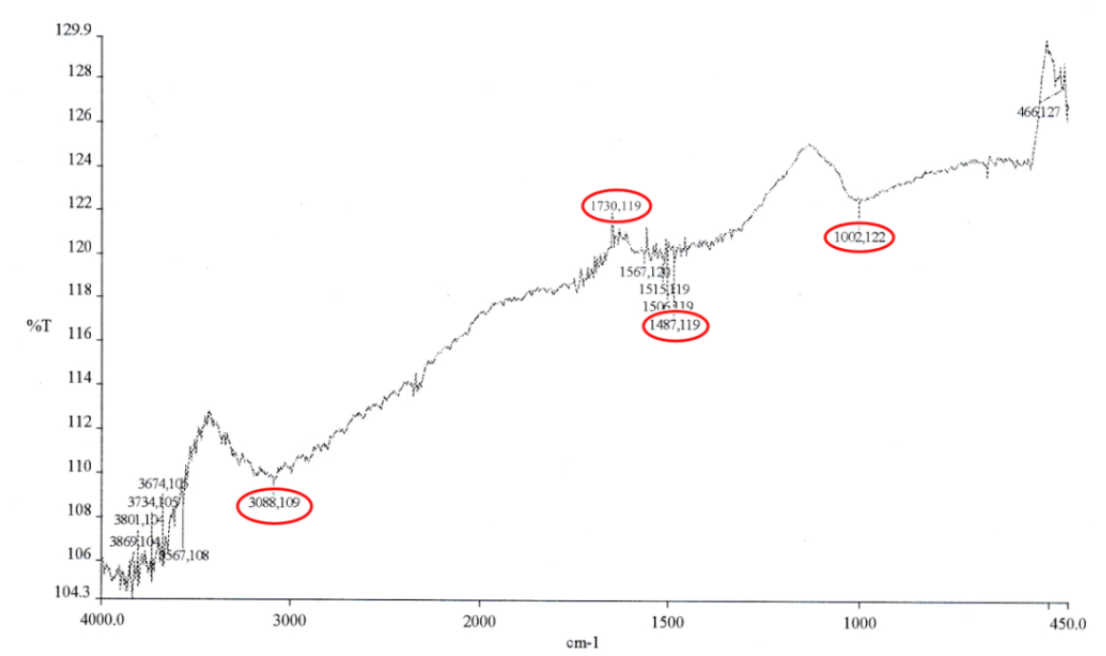

Figure 1. FTIR Spectrum of The Sample PU-Collagen-Chitosan 2\% (w/v)

The FTIR result showed several absorption bands: wavenumber $3650-3850 \mathrm{~cm}^{-1}$ that is $\mathrm{O}-\mathrm{H}$ bending vibration, wavenumber $3567 \mathrm{~cm}^{-1}$ that is secondary $\mathrm{N}-\mathrm{H}$ stretching vibration, wavenumber $3088 \mathrm{~cm}^{-1}$ that is amide $\left(\mathrm{R}^{\prime} \mathrm{NH}_{2}\right)$ bending vibration as distinct group owned by collagen, wavenumber $1730 \mathrm{~cm}^{-1}$ that is urethane (-NHCOO-) vibration, wavenumber $1487 \mathrm{~cm}^{-1}$ that is $\mathrm{CH}_{2}$ bending vibration as distinct group that chitosan has, and wavenumber $1002 \mathrm{~cm}^{-1}$ that is chitosan C-O-C stretching vibration which underwent wavenumber shift from $1080-1100 \mathrm{~cm}^{-1}$ as a result of crosslinking with $\mathrm{OH}$ group of glutaraldehyde. The best synthesis result was obtained in chitosan $2 \%(\mathrm{w} / \mathrm{v})$ coating, which is observed from the functional group. 


\section{Degradation Test Result with Simulated Body Fluid (SBF)}

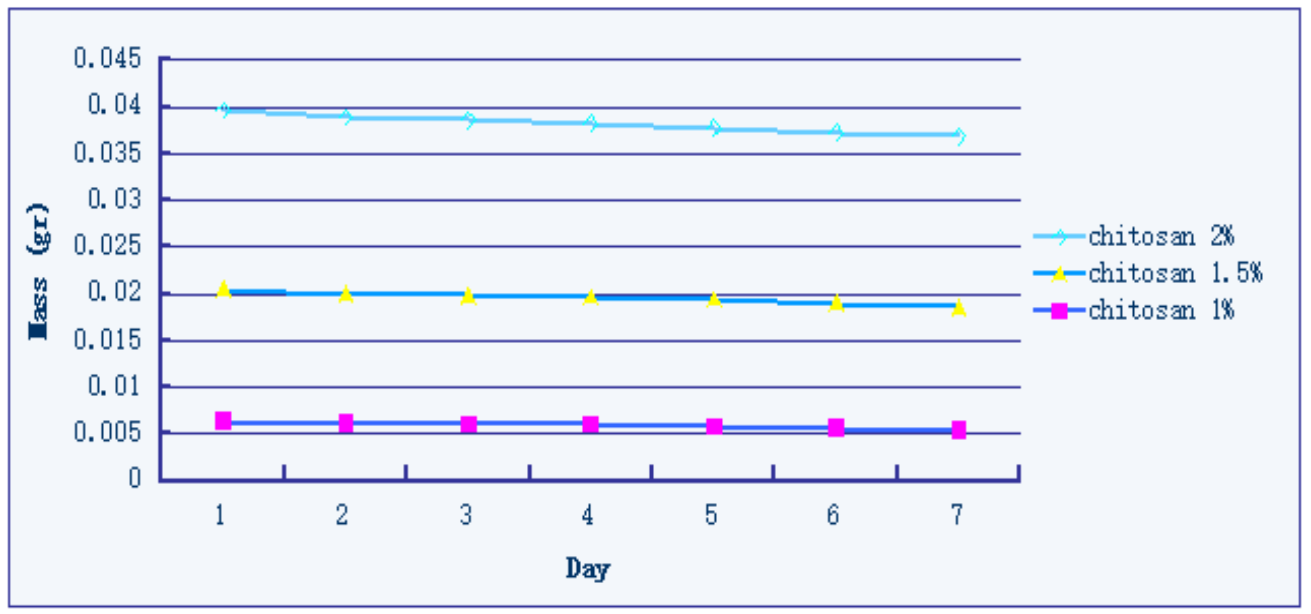

Figure 2. Graph of Mass Change With Respect to Time

According to the study of Rohaeti, et. al. [10], polyurethane can be degraded in the body after 30 days. This is in accordance with the regeneration rate of nerve mechanism, which is $1 \mathrm{~mm} /$ day or $1 \mathrm{inch} /$ month [3]. Thus it is suggested that hollowfiber polyurethane-collagen coated with chitosan has the potential to be an accelerator for the treatment of peripheral nerve injury, which is biodegradable.

\section{Tensile Test Result}

Table 2. Calculation Result of Tensile Test

\begin{tabular}{|l|c|c|c|}
\hline \multicolumn{1}{|c|}{ Sample } & $\begin{array}{c}\text { Strain } \\
(\mathbf{\%})\end{array}$ & $\begin{array}{c}\text { Stress } \\
\mathbf{( M P a )}\end{array}$ & $\begin{array}{c}\text { Modulus } \\
\text { (MPa) }\end{array}$ \\
\hline Chitosan 1\% & 115.179 & 0.0499 & 4.755 \\
\hline Chitosan 1,5\% & 114.286 & 0.0078 & 4.747 \\
\hline Chitosan 2\% & 2161.061 & 0.0109 & 7.679 \\
\hline
\end{tabular}

Table 2 shows how chitosan variation of $2 \%$ obtained the highest modulus value of 7.67 MPa. This modulus value is lower than the modulus value of polyurethane that ranges between 4-20 MPa [11] because the polyurethane coated with chitosan and glutaraldehyde casted stiffness effect, resulting in dwindling modulus value [8]. The tensile strength of the nerve, allowing protection from trauma and compression, is provided by the longitudinally oriented endoneurial and circumferential perineurial and epineurial collagen. The biocomposite of this study using collagen which is act as important composition mimicked the human nerve graft [12].

\section{The Morphology Test Result with Scanning Electron Microscope (SEM)}

Vertical SEM analysis of hollow fiber sample revealed value distribution in diameter size ranging from 2.021 to $2.032 \mathrm{~mm}$ and membrane pore size ranging from 31.33 to $39.65 \mu \mathrm{m}$ (Figure 3). This shows that the sample can be used to accelerate treatment for peripheral nerve injury. Pateman et. al. [13] stated that periphereal nerve has a diameter of $1.5-3 \mathrm{~mm}$. On a differing point, pores in hollow fiber members will ease micro fibers of nerve cells to pass through tube without hitting against one another, so peripheral nerve performance to regenerate becomes more maximum. 


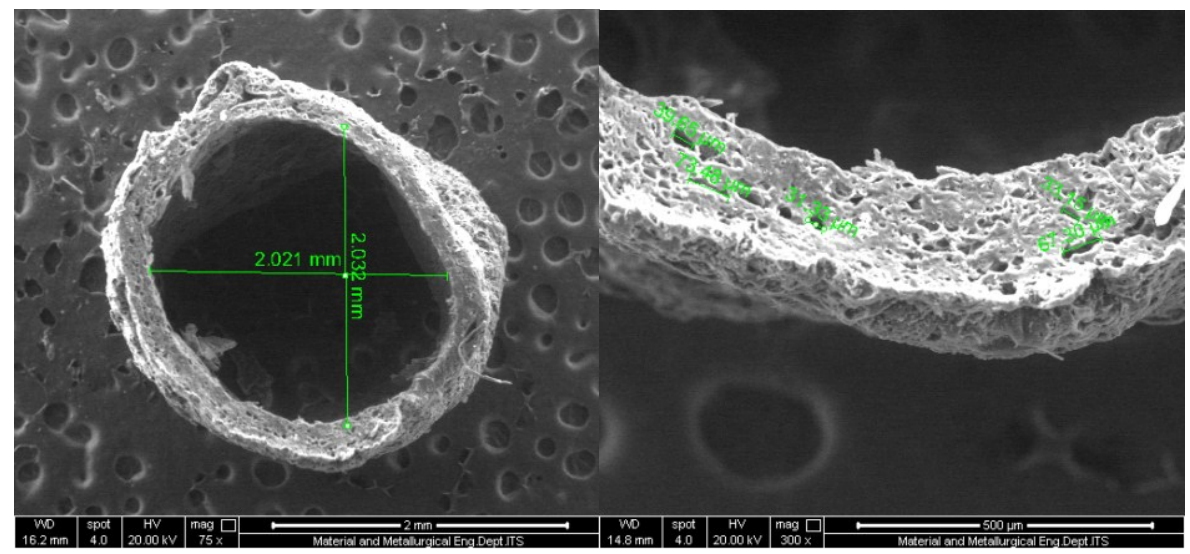

Figure 3. SEM result of hollow fiber PU-Collagen-Chitosan in horizontal display in 75x and 300x magnification that shows diameter and pore size

\section{Cytotoxicity Test Result with MTT Assay}

Based on the test result, it was discovered that the percentage of viable cells of fibroblast BHK-21 was over $100 \%$ (Figure 4). It means that the cells had proliferated. In the future, it is expected that the sample can function as propagation media for new cells when implemented. According to Spielmann et. al. [8], the percentage of viable cells that exceeds $50 \%$ confirms that the sample is not toxic.

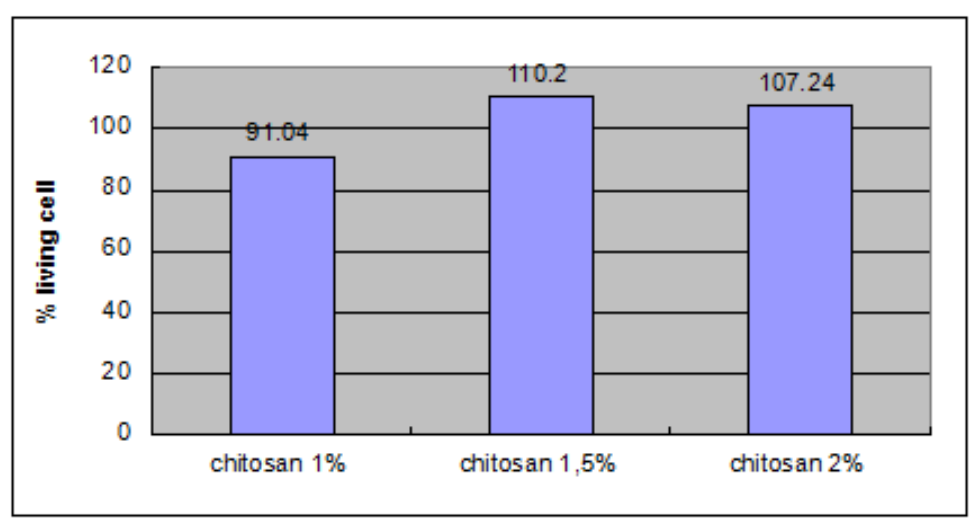

Figure 4. Graph of Viable Cell Percentage Value (\%) in Sample

\section{Conclusion}

1. Biodegradability of hollowfiber polyurethane-collagen coating chitosan because the degradation rate is appropriate with the rate of nerve mechanism.

2. The pore diameter of nerve graft artificial from morphology assay is appropriate with the standard of periphereal nerve diameter, pores function are to ease micro fibers of nerve cells to pass through tube without hitting against one another and increasing regeneration performance.

3. This biocomposite is not toxic according to the cytotoxicity result because the cell could proliferate well through the procentage of living cell.

4. Hollowfiber polyurethane-collagen coating chitosan has the potential to be modulator for peripheral nerve injury treatment. 


\section{References}

[1]. Badan Pusat Statistik. 2011. Jakarta: Statistik Transportasi (Transportation Statistics)

[2]. Uzun G, Yildiz S. 2006. The role of radiology in dive-related disorders. PMID: 16532864 [PubMed-indexed for MEDLINE].

[3]. Ijkema, Jos-Paassen. 2005. Long-term Reinnervation Effect After Sciatic Nerve Lession in Adult Rat. Volume 187, Issue 2. Pp 113-120.

[4]. Deumens R, et. al. 2010. Repairing injured peripheral nerves: Bridging the Gap. 92(3):245-76. doi: 10.1016/j.pneurobio.2010.10.002.

[5]. Cui Tongkui, et. al. 2009. Rapid Prototyping a Double-layer Polyurethane--collagen Conduit and its Schwann Cell Compatibility. Journal of Bioactive \& Compatible Polymers.

[6]. Yuan Y, et. al. 2004. The interaction of Schwann cells with chitosan membranes andfibers in vitro. Biomaterials 25:4273e8i.

[7]. Freier T, et. al. 2005. Controlling cell adhesion and degradation of chitosanfilms by Nacetylation. Biomaterials. 26:5872e8.

[8]. Kohlpaintner C., et. al. 2005. Aldehydes, Aliphatic, Ullmann's Encyclopedia of Industrial Chemistry, Weinheim: Wiley-VCH.

[9]. Spielmann H, et. al. 2007. The practical application of three validated in vitro embryotoxicity tests. ATLA, 527-538.

[10]. Rohaeti Eli, et. al. 2001. Pengaruh Maltosa Terhadap Pembentukan Poliuretan. Bandung: Institut Teknologi Bandung.

[11]. Kojio Ken, et. al. 2010. Control of Mechanical Properties of Thermoplastic Polyurethane Elastomers by Restriction of Crystallization of Soft Segment. Japan: Nagasaki University. www.mdpi.com/journal/materials.

[12]. Pateman Christopher, et. al. 2015. Nerve guides manufactured from photocurable polymers to aid peripheral nerve repair. UK: University of Sheffield. ELSEVIER Biomaterials 49 (2015) $77 \mathrm{e} 89$.

[13]. Quann D, Bird SJ, 1999. Nerve Conduction Studies and Electromyography in the Evaluation of Peripheral Nerve Injuries. The University of Pennsylvania Orthopaedic Journal 12: 45-51, 1999, p 45-51 
Journal of Biomimetics, Biomaterials and Biomedical Engineering Vol. 28

10.4028/www.scientific.net/JBBBE.28

\section{Hollowfiber Polyurethane-Collagen Coating Chitosan as Nerve Graft for Therapy of Peripheral Nerve Injury in Extreme Paralysis}

10.4028/www.scientific.net/JBBBE.28.78

\section{DOI References}

[3] Ijkema, Jos-Paassen. 2005. Long-term Reinnervation Effect After Sciatic Nerve Lession in Adult Rat.

Volume 187, Issue 2. Pp 113-120.

10.1016/j.aanat.2004.11.001

[5] Cui Tongkui, et. al. 2009. Rapid Prototyping a Double-layer Polyurethane-collagen Conduit and its Schwann Cell Compatibility. Journal of Bioactive \& Compatible Polymers.

10.1177/0883911509102349

[8] Kohlpaintner C., et. al. 2005. Aldehydes, Aliphatic, Ullmann's Encyclopedia of Industrial Chemistry, Weinheim: Wiley-VCH.

10.1002/14356007.a01_321

[11] Kojio Ken, et. al. 2010. Control of Mechanical Properties of Thermoplastic Polyurethane Elastomers by Restriction of Crystallization of Soft Segment. Japan: Nagasaki University. www. mdpi.

com/journal/materials.

$10.3390 / \mathrm{ma} 3125097$

[12] Pateman Christopher, et. al. 2015. Nerve guides manufactured from photocurable polymers to aid peripheral nerve repair. UK: University of Sheffield. ELSEVIER Biomaterials 49 (2015) 77e89.

10.1016/j.biomaterials.2015.01.055 